Check for updates

The BMJ

Cite this as: $B M J 2021 ; 372: \mathrm{n} 230$ http://dx.doi.org/10.1136/bmi.n230 Published: 26 January 2021

\section{Covid-19: New UK variant may be linked to increased death rate, early data indicate}

\author{
Gareth lacobucci
}

The new UK variant of SARS-CoV-2 may be associated with an increased risk of death, emerging data are suggesting.

In a briefing paper published on 22 January the government's New and Emerging Respiratory Virus Threats Advisory Group (NERVTAG) highlighted several preliminary analyses showing a possible increase in the severity of disease associated with the new variant of concern (VOC) B.1.1.7, which first emerged in Kent in September. ${ }^{1}$

Two unpublished papers, one from the London School of Hygiene and Tropical Medicine and one from Imperial College London, ${ }^{23}$ reported an increased case fatality rate in people with s-gene target failure (SGTF, a proxy for variant B.1.1.7). Both studies analysed cases of the new and old variant by linking community testing data with death data.

"Based on these analyses, there is a realistic possibility that infection with VOC B.1.1.7 is associated with an increased risk of death compared to infection with non-VOC viruses," the briefing paper said.

The prime minister, Boris Johnson, referred to the data at a Downing Street press briefing on 22 January, where the government's chief scientific adviser, Patrick Vallance, said that the preliminary analyses suggested that in every 1000 men aged 60 years who were infected with the new variant 13 or 14 might be expected to die, compared with 10 in 1000 infected with the original variant.

NERVTAG said that further analysis was needed because the data involved a relatively small number of people (around $8 \%$ of the total deaths occurring during the study period) and did not include data on hospital admission.

At a Science Media Centre briefing on 25 January Peter Horby, professor of emerging infectious diseases at the University of Oxford and chair of NERVTAG, said, "What the analysis so far shows is that the rates of death when you link community testing to death is higher in those with the B.1.1.7 variant than matched people with the other virus variant.

"But what we have not been able to detect yet is an increased rate of hospitalisation, or once in hospital, an increased rate of dying with this variant versus another variant, so that's where the uncertainty lies ... and that's where the work is needed."

John Edmunds, professor in the Centre for the Mathematical Modelling of Infectious Diseases at the London School of Hygiene and Tropical Medicine and member of NERVTAG, said that, despite the uncertainty, he believed that the government "was right to raise it."
"The evidence is pretty solid," he told the briefing. "Yes, we would like to look at other datasets, particularly the hospitalisation datasets. But ... there is quite a lot of evidence, and the effect is not small."

The London School's analysis was based on 2583 deaths among 1.2 million tested individuals; 384 deaths were among people with SGTF. The relative hazard of death within 28 days of a test for VOC infected people in comparison with people with the original variant was 1.35 (95\% confidence interval 1.08 to 1.68 ).

Imperial's study found that the mean ratio of case fatality rate in VOC infected people versus non-VOC was 1.36 (1.18 to 1.56), when calculated in a case-control weighting method, and 1.29 (1.07 to 1.54) in a standardised case fatality rate method.

NERVTAG also cited a subsequent independent case-control analysis of community testing data linked to death data by Exeter University, which found that the mortality hazard ratio for VOC infected people, versus non-VOC, was 1.91 (1.35 to 2.71).

The analyses were all adjusted for age, location, time, and other variables.

And an updated matched cohort analysis of 14939 SGTF cases and 15555 comparators from Public Health England identified 65 deaths among non-SGTF cases $(0.1 \%)$ and 104 deaths among SGTF cases $(0.2 \%)$, within 28 days of specimen date. This gave a death risk ratio for VOC infected people versus non-VOC of 1.65 (1.21 to 2.25). 4

A separate rapid analysis of data from one NHS trust from the Covid-19 Clinical Information Network (CO-CIN) did not find an increased risk of death among people admitted to hospital when it compared patients with proved VOC $(\mathrm{n}=32)$ with patients without VOC $(\mathrm{n}=184)$ (odds ratio 0.63 (0.20 to 1.69). ${ }^{5}$ But NERVTAG said more work was needed to understand the effect of variant on risk.

NERVTAG noted that the absolute risk of death per infection "remains low."

Commenting on the data, David Spiegelhalter, chair of the Winton Centre for Risk and Evidence Communication at the University of Cambridge, said, "The baseline risks go up steeply with age, so for those in their 8os the new variant would take the average mortality risk from $8 \%$ to around $10 \%$ and for those in 90 from around $20 \%$ to $27 \%$-a massive impact. But for those in their $40 \mathrm{~s}$ it goes from around 1 in 500 to 1.3 in 500, and for those in their 20 from 1 in 3000 to 1.3 in 3000 , a trivial increase."

NERVTAG paper on COVID-19 variant of concern B.1.1.7: paper from the New and Emerging Respiratory Virus Threats Advisory Group (NERVTAG) on new coronavirus (COVID-19) variant B.1.1.7. https://www.gov.uk/government/publications/nervtag-paper-on-covid-19-variant-of-concern-b117. 
2 Davies N, Diaz-Ordaz K, Keogh R. 2021. Relative fatality hazard in Pillar 2 tested individuals with VOC. LSHTM. https://assets.publishing.service.gov.uk/government/uploads/system/uploads/attachment_data/file/955239/NERVTAG_paper_on_variant_of_concern__VOC_B.1.1.7.pdf.

3 Ferguson N. 2021. Non-parametric analysis of fatal outcomes associated with B1.1.7. Imperial College London. https://assets.publishing.service.gov.uk/government/uploads/system/uploads/attachment_data/file/955239/NERVTAG_paper_on_variant_of_concern_VOC_B.1.1.7.pdf.

4 Public Health England. Unpublished analysis. 2021. https://assets.publishing.service.gov.uk/government/uploads/system/uploads/attachment_data/file/955239/NERVTAG_paper_on_variant_of_concern_VOC_B.1.1.7.pdf.

5 Docherty A, Harrison E, Semple C. 2021. Hospital case fatality and emergence of variant of concern B.1.1.7, rapid CO-CIN report to NERVTAG and SAGE: unpublished analysis. https://assets.publishing.service.gov.uk/government/uploads/system/uploads/attachment_data/file/955239/NERVTAG_paper_on_variant_of_concern_VOC_B.1.1.7.pdf.

This article is made freely available for use in accordance with BMJ's website terms and conditions for the duration of the covid-19 pandemic or until otherwise determined by BMJ. You may use, download and print the article for any lawful, non-commercial purpose (including text and data mining) provided that all copyright notices and trade marks are retained. 